\title{
Effect of beta-mercaptoethanol during in vitro fertilization procedures on sperm penetration into porcine oocytes and the early development in vitro
}

\author{
Hiroaki Funahashi \\ The Graduate School of Natural Science and Technology, Okayama University, Tsushima-Naka, Okayama \\ 700-8530, Japan \\ Correspondence should be addressed to H Funahashi; Email: hirofun@cc.okayama-u.ac.jp
}

\begin{abstract}
This study was carried out to determine the effects of beta-mercaptoethanol (bME) during a transient co-culture of gametes for $10 \mathrm{~min}$, and/or the following culture until 6-9 $\mathrm{h}$ after insemination, on sperm penetration of porcine in vitro maturation (IVM) oocytes and the early development in vitro. When fresh spermatozoa were cultured in various concentrations of bME for $\mathbf{2 h}$, bME neutralized the stimulatory effect of caffeine-benzoate on sperm capacitation and the spontaneous acrosome reaction at $50-250 \mu \mathrm{mol} / \mathrm{l}$. When $50 \mu \mathrm{mol} / \mathrm{l} \mathrm{bME}$ were added during a transient co-culture of gametes for $10 \mathrm{~min}$, the sperm penetration rate was reduced $9 \mathrm{~h}$ after insemination (70.5-82.0\% vs $90.5-94.0 \%$ in the absence of bME), but the incidence of monospermic penetration was not affected. When $50 \mu \mathrm{mol} / \mathrm{l} \mathrm{bME} \mathrm{were} \mathrm{supplemented} \mathrm{during} \mathrm{culture} \mathrm{after} \mathrm{a} \mathrm{transient} \mathrm{co-culture,} \mathrm{the}$ sperm penetration rate was not affected, but the incidence of monospermy oocytes was increased $(43.9-45.8 \%$ vs $31.7-34.3 \%$ in the absence of bME). The presence of bME following a transient co-culture minimized a decrease of oocyte glutathione content at $6 \mathrm{~h}$ after insemination $(7.9 \mathrm{pmol} / \mathrm{oocyte}$ before in vitro fertilization (IVF), $6.7 \mathrm{pmol} / \mathrm{oocyte}$ in the presence of bME vs $5.5 \mathrm{pmol} / \mathrm{oocyte}$ in the absence of $\mathrm{bME})$. When the distribution of cortical granules was evaluated $1 \mathrm{~h}$ after activation with calcium ionophore, mean pixel intensity of fluorescein isothiocyanate-labeled peanut agglutinin (FITC-PNA) at the cortex region was lower in the oocytes activated and cultured in the presence of $50 \mu \mathrm{mol} / \mathrm{l} \mathrm{bME}$. Although the presence of $50 \mu \mathrm{mol} / \mathrm{l} \mathrm{bME}$ during a transient co-culture for $10 \mathrm{~min}$ and the following culture did not increased blastocyst formation (29.6-37.7\%), $50 \mu \mathrm{mol} / \mathrm{l}$ bME during the following culture significantly increased the mean cell numbers per blastocyst (73.3-76.4 vs 51.2 in the presence and absence of bME respectively). These results demonstrate that supplementation with bME during IVF procedures, except during a transient co-culture period of gametes in the presence of caffeine, has a beneficial effect in maintaining the function of gametes, the incidence of normal fertilization and, consequently, the quality of IVF embryos.

Reproduction (2005) 130 889-898
\end{abstract}

\section{Introduction}

A high incidence of polyspermic penetration is still constituting a major obstacle in the in vitro production of normal porcine embryos (Funahashi 2003), although historical problems, such as unsuccessful male pronuclear formation and low developmental competence, have been overcome by reducing oxidative stress with thiols during in vitro maturation (IVM) and culture (IVC) for early development. Supplementation with antioxidants - such as beta-mercaptoethanol (bME) and cysteamine - during IVM has been found to improve intracellular glutathione content in oocytes and the developmental competence after in vitro fertilization (IVF) in several species (Comizzoli et al. 2000, Mizushima \& Fukui 2001, de Matos et al. 2002, Songsasen \& Apimeteetumrong 2002, Rodriguez-Gonzalez et al.
2003). In pigs, the addition of cysteine and bME during IVM also enhanced the incidence of male pronuclear formation and the developmental competence of IVF embryos (Funahashi et al. 1997, Abeydeera et al. 1998). However, bME in IVM medium has been known to improve the quality of blastocysts, as determined by the cell number, but not the efficiency of in vitro blastocyst formation in cows (Takahashi et al. 2002), swamp buffalo (Songsasen \& Apimeteetumrong 2002) and sheep (de Matos et al. 2002). Furthermore, the incidence of blastocyst formation and the quality of embryos have also been increased by reducing the oxidative stress during IVC of IVM-IVF porcine embryos (Kikuchi et al. 2002). However, little is known about the effect of antioxidants, such as bME, during the IVF period on the penetrability of spermatozoa into porcine oocytes 
and on early development. Supplementation with thiol components during IVF procedures may be beneficial to the oocyte quality, and consequently to the incidences of normal fertilization and the developmental competence. Since reactive oxygen species like superoxide anion or hydrogen peroxide have been suggested to promote sperm capacitation in humans (de Lamirande \& Gagnon 1993, Leclerc et al. 1997), the presence of bME may prevent sperm capacitation, as an oxidative reaction. In fact, the addition of antioxidants during a conventional IVF period has been demonstrated to reduce penetration rates (Blondin et al. 1997) and the subsequent development of bovine embryos to the morula and blastocyst stages (Ali et al. 2003).

Recently, the author and a colleague found that a transient co-culture of porcine oocytes with spermatozoa in the presence of caffeine followed by an additional culture in the absence of sperm cells and caffeine effectively decreased the incidence of polyspermic penetration without any reduction in the penetration rate (Funahashi \& Romar 2004). Since this new in vitro fertilization (IVF) system can separate the process of sperm capacitation and zona binding from the following process of sperm penetration under different conditions, this system may be useful in analyzing further details of the effects of bME during the IVF period.

Therefore, the major objectives of the present study were: to determine the effect of bME addition during a transient co-culture period on sperm capacitation and zona binding; and to determine the effects of addition of bME to the following culture medium on sperm penetration in IVF of porcine IVM oocytes, and also early development.

\section{Materials and Methods \\ Chemicals and culture media}

$\mathrm{KCl}, \mathrm{KH}_{2} \mathrm{PO}_{4}, \mathrm{MgCl}_{2} \cdot 6 \mathrm{H}_{2} \mathrm{O}, \mathrm{CaCl}_{2} \cdot 2 \mathrm{H}_{2} \mathrm{O}$, sodium citrate and citric acid were purchased from Ishizu Pharmaceutical Co., Ltd (Osaka, Japan). $\mathrm{NaCl}$ and paraffin liquid were obtained from Nacalai Teque Inc. (Kyoto, Japan). Other chemicals were purchased from Sigma.

The medium used for the collection of oocyte-cumulus complexes and washing was modified TL-HEPES-PVA medium composed of $114 \mathrm{mmol} \mathrm{NaCl} / \mathrm{l}, 3.2 \mathrm{mmol} \mathrm{KCl} / \mathrm{l}$,

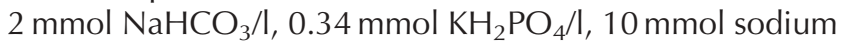
lactate/l, $0.5 \mathrm{mmol} \mathrm{MgCl} \cdot 6 \mathrm{H}_{2} \mathrm{O} / \mathrm{l}, 2 \mathrm{mmol} \mathrm{CaCl} \cdot 2 \mathrm{H}_{2} \mathrm{O} / \mathrm{l}$, $10 \mathrm{mmol} \mathrm{HEPES} / \mathrm{l}, 0.2 \mathrm{mmol}$ sodium pyruvate $/ \mathrm{l}, 12 \mathrm{mmol}$ sorbitol/l, $0.1 \%(\mathrm{w} / \mathrm{v})$ polyvinylalcohol, $25 \mu \mathrm{g}$ gentami$\mathrm{cin} / \mathrm{ml}$ and $65 \mu \mathrm{g}$ potassium penicillin $\mathrm{G} / \mathrm{ml}$. The basic IVM medium (OMM37) used was BSA-free North Carolina State University 37 (NCSU37) medium (Petters \& Wells 1993) supplemented with $0.6 \mathrm{mmol}$ cysteine/l, $5 \mu \mathrm{g}$ insulin $/ \mathrm{ml}$, $50 \mu \mathrm{mol} \mathrm{bME} / \mathrm{l}$ and $10 \%(\mathrm{v} / \mathrm{v})$ porcine follicular fluid (Funahashi et al. 1997). The basic IVF medium was modified Medium199 (m-M199), which is Medium199 with Earle's salts (Gibco; Invitrogen Corp.) supplemented with
$3.05 \mathrm{mmol}$ glucose $/ \mathrm{l}, 2.92 \mathrm{mmol}$ hemi-calcium lactate/l, $0.91 \mathrm{mmol}$ sodium pyruvate $/ \mathrm{l}, 12.00 \mathrm{mmol}$ sorbitol $/ \mathrm{l}, 25 \mu \mathrm{g}$ gentamicin $/ \mathrm{ml}, 65 \mu \mathrm{g}$ potassium penicillin $\mathrm{G} / \mathrm{ml}$, and $0.4 \%$ $(\mathrm{w} / \mathrm{v})$ BSA (Sigma; catalog number A4378). The medium used as semen diluent was modified Modena solution prepared with $152.64 \mathrm{mmol}$ glucose $/ \mathrm{l}, 23.46 \mathrm{mmol}$ sodium citrate/l, $11.9 \mathrm{mmol} \mathrm{NaHCO}_{3} / \mathrm{l}, 6.99 \mathrm{mmol}$ EDTA-2Na/l, $46.66 \mathrm{mmol}$ Tris/l, $15.10 \mathrm{mmol}$ citric acid/l and $25 \mathrm{mg}$ gentamicin sulfate/l. All media without modified TL-HEPES-PVA and modified Modena solution were equilibrated under paraffin liquid at $39^{\circ} \mathrm{C}$ in an atmosphere of $5 \% \mathrm{CO}_{2}$ in air overnight prior to incubation with oocytes. Porcine follicular fluid was prepared from antral follicles $(3-6 \mathrm{~mm}$ in diameter) as described previously (Funahashi et al. 1994a).

\section{Preparation and culture of cumulus-oocyte complexes}

Ovaries were collected from slaughtered prepubertal gilts at a local abattoir and transported to the laboratory in $0.9 \% \mathrm{NaCl}$ containing $75 \mathrm{mg}$ potassium penicillin $\mathrm{G} / \mathrm{l}$ and $50 \mathrm{mg}$ streptomycin sulfate/l. Cumulus-oocyte complexes were aspirated through an 18-gauge needle into a disposable $10 \mathrm{ml}$ syringe from antral follicles $(3-6 \mathrm{~mm}$ in diameter) on the surface of ovaries, washed three times with modified TL-HEPES-PVA medium, and then collected in a fresh modified TL-HEPES-PVA medium at room temperature (Wongsrikeao et al. 2004). Oocytes were matured in an IVM system that has been reported to produce blastocysts and piglets efficiently following IVF and embryo transfer (Funahashi et al. 1997). Briefly, 50 cumulusoocyte complexes with uniform ooplasm and a compact cumulus cell mass were washed three times with OMM37 supplemented with $1 \mathrm{mmol}$ dibutyryl cAMP/l, 10 iu equine chorionic gonadotropin (eCG)/ml and 10 iu human chorionic gonadotropin $(\mathrm{hCG}) / \mathrm{ml}$, and subsequently cultured in $500 \mu \mathrm{l}$ of the same medium covered with paraffin oil for $20 \mathrm{~h}$ at $39^{\circ} \mathrm{C}$ in an atmosphere of $5 \% \mathrm{CO}_{2}$ in air. The complexes were then transferred to $500 \mu \mathrm{l}$ OMM37 (without dibutyryl cAMP, eCG and hCG) after washing three times with the same medium. The complexes were cultured for an additional 24h (Funahashi et al. 1994a). After culture, oocytes were stripped of cumulus cells by pipetting with $0.1 \%(\mathrm{w} / \mathrm{v})$ hyaluronidase and were washed three times with m-M199.

\section{Preparation of fresh boar spermatozoa}

Semen-rich fractions $(30-50 \mathrm{ml})$ were collected from a Berkshire boar by the gloved-hand method at a local experimental station and were diluted four times with modified Modena solution. The diluted semen samples were transported to the laboratory within $2 \mathrm{~h}$ of collection. After washing once by centrifugation at $750 \mathrm{~g}$ for $3 \mathrm{~min}$, spermatozoa were re-suspended at a concentration of $1 \times 10^{8}$ cells $/ \mathrm{ml}$ in modified Modena solution containing $5 \mathrm{mmol}$ cysteine/l and $20 \%(\mathrm{v} / \mathrm{v})$ boar seminal plasma (Funahashi \& Sato 2005). Diluted sperm suspension was 
kept overnight at room temperature. Just before use, stored spermatozoa were washed three times by centrifugation at $750 \mathrm{~g}$ for $3 \mathrm{~min}$ with modified TL-HEPES-PVA solution and then re-suspended at a concentration of $1 \times 10^{8}$ cells $/ \mathrm{ml}$ in m-M199.

\section{In vitro fertilization}

After dilution to $5 \times 10^{5}$ cells/ml with m-M199, $50 \mu l$ diluted sperm suspension were inseminated in the same volume of m-M199 containing $10 \mathrm{mmol}$ caffeine-benzoate/l (final concentrations of spermatozoa and caffeine-benzoate were $2.5 \times 10^{5}$ cells $/ \mathrm{ml}$ and $5 \mathrm{mmol} / \mathrm{l}$ respectively). Thirty denuded oocytes were co-cultured with spermatozoa in $100 \mu \mathrm{l}$ droplets under paraffin oil for $10 \mathrm{~min}$. The oocytes were gently washed once with sperm-free and caffeine-free m-M199, transferred to a $500 \mu$ l well of fresh caffeine-free m-M199 and the culture continued for 6 or $9 \mathrm{~h}$ at $39{ }^{\circ} \mathrm{C}$ in an atmosphere of $5 \% \mathrm{CO}_{2}$ in air.

\section{Parthenogenetic oocyte activation and labeling oocytes with fluorescein isothiocyanate-labeled peanut agglutinin (FITC-PNA)}

Denuded oocytes were washed three times with m-M199 containing 5 mmol caffeine-benzoate/l (m-M199-caffeine) and treated with $100 \mu \mathrm{mol}$ calcium ionophore/l (Wang et al. 1998b) in the same medium for 5 min for parthenogenetic activation. After the treatment, oocytes were washed three times with m-M199-caffeine, transferred to a $500 \mu \mathrm{l}$ well of fresh m-M199-caffeine and then the culture continued for $1 \mathrm{~h}$ at $39^{\circ} \mathrm{C}$ in an atmosphere of $5 \% \mathrm{CO}_{2}$ in air.

After the culture, the oocytes were washed once with TL-HEPES-PVA and fixed with 3\% paraformaldehyde in TL-HEPES-PVA for $30 \mathrm{~min}$ at room temperature. As described in a previous report (Katayama et al. 2002), the oocytes were processed and stained with $20 \mu \mathrm{g}$ lectin $/ \mathrm{ml}$ from Archis hypogaea (peanut)-conjugated FITC (FITC$\mathrm{PNA}$ ) and $400 \mu \mathrm{l}$ propidium iodide/ml for $30 \mathrm{~min}$. After rinsing, the oocytes were mounted in an anti-fade medium. The surface of the oocyte was observed using a confocal laser scanning microscope (MRC1024, Nippon Bio-Rad Laboratories, Tokyo, Japan).

\section{Chlortetracycline (CTC) fluorescence assessment of spermatozoa}

The methods used for CTC analysis were essentially those described previously (Funahashi et al. 2000) with minor modification. Briefly, $8 \mu \mathrm{l}$ of $100 \mu \mathrm{g}$ Hoechst bis-benzimide $33258 / \mathrm{ml}$ was added to $792 \mu \mathrm{l}$ of sperm suspension. After mixing, each suspension was incubated for $3 \mathrm{~min}$ at room temperature in the dark, then layered onto $3 \mathrm{ml}$ of $3 \%(\mathrm{w} / \mathrm{v})$ polyvinylpyrolidone (PVP-40) in TL-HEPES-PVA and centrifuged at $750 \mathrm{~g}$ for $3 \mathrm{~min}$. The pelleted spermatozoa were resuspended in $45 \mu \mathrm{l}$ TL-HEPES-PVA and $45 \mu \mathrm{l}$ of this suspension were added to $45 \mu$ l CTC solution, containing $750 \mu \mathrm{mol} C \mathrm{CTC} /, 5 \mathrm{mmol}$ cysteine- $\mathrm{HCl} / \mathrm{l}$,
$130 \mathrm{mmol} \mathrm{NaCl} / \mathrm{l}$ and $20 \mathrm{mmol}$ Tris/l (pH 7.8). Sperm cells were fixed by adding $8 \mu \mathrm{l}$ of $12.5 \%(\mathrm{w} / \mathrm{v})$ paraformaldehyde in $0.5 \mathrm{~mol}$ Tris $-\mathrm{HCl} / \mathrm{l}(\mathrm{pH} \mathrm{7.4)}$. The CTC solution was prepared daily. Slides were prepared by placing $10 \mu \mathrm{l}$ of the fixed sperm suspension on a slide and one drop of $0.22 \mathrm{~mol}$ 1,4-diazabicyclo[2.2.2] octane/l dissolved in glycerol:TL-HEPES-PVA $(9: 1)$ which was then mixed in order to retard the fading of fluorescence. A coverslip was added and sealed with colorless nail varnish. Spermatozoa were assessed under a phase-contrast microscope, equipped with epifluorescent optics, on the same day. Each cell was first observed under u.v. illumination (excitation at $330-380 \mathrm{~nm}$, emission at $420 \mathrm{~nm}$ ) to determine the live/dead status; the sperm cells showing bright blue staining of the nucleus were considered to be dead and were not counted. More than 100 live sperm were then examined under blue-violet illumination (excitation at $400-440 \mathrm{~nm}$, emission at $470 \mathrm{~nm}$ ) and classified according to CTC staining patterns. The three fluorescent staining patterns identified were: $F$, with uniform fluorescence over the whole sperm head; $B$, with a fluorescence-free band in the post-acrosome region; $A R$, with almost no fluorescence over the sperm head except for a thin band of fluorescence in the equatorial segment.

\section{Glutathione assay}

Five microliters of $1.25 \mathrm{M}$ phosphoric acid was added to a $1.5 \mathrm{ml}$ microfuge tube containing 30-50 oocytes in $5 \mu \mathrm{l}$ of $0.2 \mathrm{M}$ sodium phosphate supplemented with $10 \mathrm{mM}$ EDTA ( $\mathrm{pH} 7.2$, stock buffer). The samples were stored in a freezer $\left(-80^{\circ} \mathrm{C}\right)$ until assayed. The total content of glutathione per oocyte was determined using the $5,5^{\prime}$ dithiobis(2-nitrobenzoic acid)-glutathione disulfide (DTNB-GSSG) reductase recycling assay (Anderson 1985) with modification (Funahashi et al. 1994b). Briefly, $700 \mu \mathrm{l}$ of $0.33 \mathrm{mg} \mathrm{NADPH} / \mathrm{ml}$ in stock buffer, $100 \mu \mathrm{l}$ of $6 \mathrm{mM}$ DTNB in the stock buffer and $190 \mu$ l water were added with mixing into the microfuge tube. To initiate the reaction, $10 \mu$ l glutathione reductase were added with mixing. The formation of 5-thio-2-nitrobenzoic acid was followed continuously with a spectrophotometer (Ultraspec-2000, Pharmacia Biotech Ltd, Cambridge, UK) from $30 \mathrm{~s}$ to 3 min of reaction with a reading recorded every $15 \mathrm{~s}$. Glutathione standards $(0.05-1.0 \mathrm{nmol})$ and a sample lacking glutathione were also assayed. The total content of glutathione was determined (Calvin et al. 1986).

\section{Experimental design}

The experimental design is schematically represented in Fig. 1. In the first experiment, the effect of bME on sperm function was examined using the CTC fluorescence assessment. Washed and re-suspended spermatozoa were diluted at $1 \times 10^{6}$ cells $/ \mathrm{ml}$ in $\mathrm{m}-\mathrm{M} 199$-caffeine and various concentrations $(0,2,10,50$ and $250 \mu \mathrm{mol} / \mathrm{l})$ of bME and then cultured for $2 \mathrm{~h}$ at $39^{\circ} \mathrm{C}$ in an atmosphere of $5 \%$ 
Experiment. 1. Effect of bME on sperm characteristics

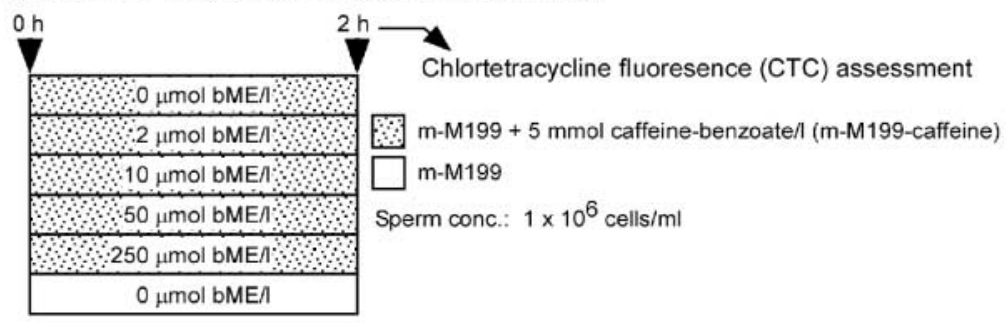

Experiment. 2. Effect of bME on sperm penetration

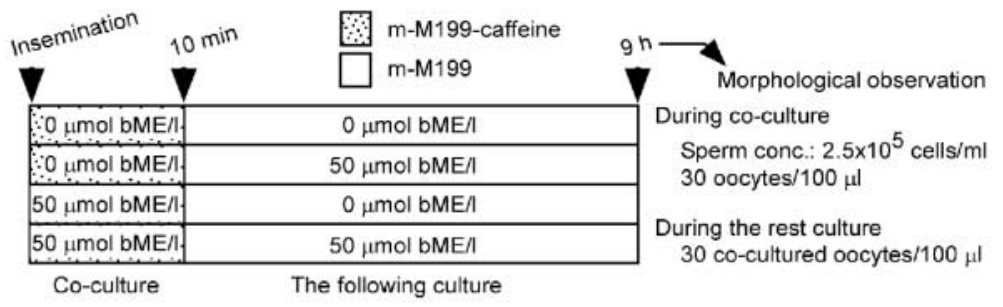

Experiment. 3. Effect of bME on intracellular glutathione content in IVF oocytes

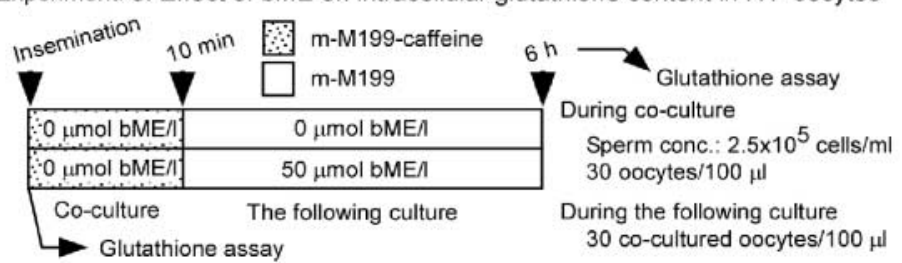

Experiment. 4. Effect of bME on cortical granule exocytosis

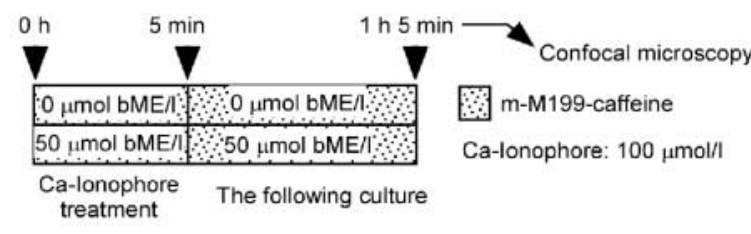

Experiment. 5. Effect of bME during IVF on early development

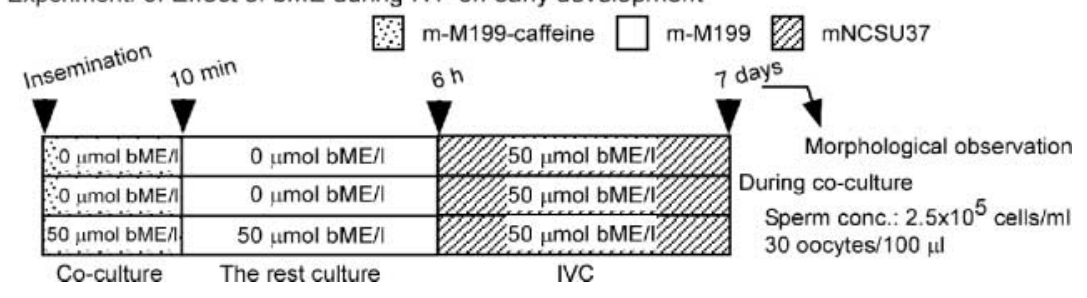

Figure 1 Schematic representation of experimental design, showing the different treatments.

$\mathrm{CO}_{2}$ in air. After the culture, CTC patterns of these sperm cells were compared with those of spermatozoa cultured in bME-free and caffeine-free m-M199. Data were obtained from eight replicated experiments.

In the second experiment, the effect of bME during a transient co-culture of gametes - and/or an additional culture following the co-culture period - on sperm penetration was examined. Denuded oocytes were cocultured with spermatozoa in the absence or presence of $50 \mu \mathrm{mol}$ bME/l in m-M199-caffeine for $10 \mathrm{~min}$, transferred to sperm-free and caffeine-free m-M199 with or without addition of $50 \mu \mathrm{mol} \mathrm{bME} / \mathrm{l}$ and then cultured at $39^{\circ} \mathrm{C}$ in an atmosphere of $5 \% \mathrm{CO}_{2}$ in air. At $9 \mathrm{~h}$ after insemination, the cultured eggs were fixed, stained with $1 \%(\mathrm{w} / \mathrm{v})$ orcein and examined at $\times 200$ and $\times 400$ magnification. Oocytes were designated as penetrated when they had at least one sperm head, a decondensed sperm nucleus or a male pronucleus and corresponding sperm tail in the vitellus. Data were obtained from eight or ten replicated experiments.

In the third experiment, the effect of bME during the culture following a transient co-culture on oocyte glutathione content was examined. After a transient co-culture with spermatozoa for $10 \mathrm{~min}$, oocytes were cultured in the absence or presence of $50 \mu \mathrm{mol} \mathrm{bME} / \mathrm{l}$. At $6 \mathrm{~h}$ after insemination, 30-50 morphologically normal oocytes were sampled to determine intracellular glutathione content. Data were obtained from 5 or 6 replicated experiments. 
In the fourth experiment, the effect of bME on the exocytosis of cortical granules after oocyte activation was examined. In the absence or presence of $50 \mu \mathrm{mol}$ bME/l, denuded oocytes were treated with $100 \mu \mathrm{mol}$ calcium ionophore/l in m-M199-caffeine for $5 \mathrm{~min}$ and then cultured in m-M199-caffeine for $1 \mathrm{~h}$. Cultured oocytes were fixed, labeled with FITC-PNA and propidium iodide and then the fluorescence was observed in the cortex region of the oocyte under a confocal laser scanning microscope. To compare the degree of cortical reaction, the mean pixel intensity of the cortex region of the oocyte was measured using the accessory software of the Laser Scanning Confocal Imaging System (LaserSharp; Nippon BioRad Laboratories, Tokyo, Japan). Values taken out the background intensity were compared. Data were obtained from four replicated experiments.

In the last experiment, the in vitro development of oocytes fertilized in the absence and presence of bME was examined. After a transient co-culture with spermatozoa at a concentration of $2.5 \times 10^{5}$ cells $/ \mathrm{ml}$ in the absence or presence of $50 \mu \mathrm{mol} \mathrm{bME} / \mathrm{l}$ in $\mathrm{m}-\mathrm{M} 199$-caffeine for $10 \mathrm{~min}$ at $39{ }^{\circ} \mathrm{C}$ in an atmosphere of $5 \% \mathrm{CO}_{2}$ in air, the oocyte culture continued in caffeine-free m-M199 containing $50 \mu \mathrm{mol} \mathrm{bME} / \mathrm{l}$. As controls, some oocytes were not exposed to bME during the transient co-culture and the following culture until $6 \mathrm{~h}$ after insemination. Those oocytes were then moved again to modified NCSU37 medium supplemented with $0.4 \%$ (w/v) BSA (Sigma, A8022), $0.6 \mathrm{mmol}$ cysteine/l, $50 \mu \mathrm{mol}$ bME/l and $5 \mu \mathrm{g}$ insulin $/ \mathrm{ml}$ and then cultured for 7 days at $39^{\circ} \mathrm{C}$ in an atmosphere of $5 \% \mathrm{CO}_{2}$ in air. Data were obtained from four replicated experiments.

\section{Statistical analysis}

Statistical analyses of results were used for treatment comparisons and were carried out by one- or two-way ANOVA using the JMP 5.0 (SAS Institute, Inc., Cary, NC, USA) program. If the $P$ value was smaller than 0.05 in ANOVA, Tukey-Kramer's HSD test was carried out using the same program. All percentage data were subjected to arc-sine transformation before statistical analysis. In order to show percentage data in tables, those data were transformed back to the original percentages. All data were expressed as means \pm S.E.M. $P \leq 0.05$ was considered to be statistically significant.

\section{Results}

\section{Effect of bME on the CTC pattern of spermatozoa (experiment 1)}

The presence of bME affected CTC patterns when spermatozoa were cultured in m-M199-caffeine for $2 \mathrm{~h}$ (Fig. 2). In bME-free medium, the presence of $5 \mathrm{mmol}$ caffeinebenzoate/l in m-M199 decreased the incidence of intact ( $F$ pattern) cells and increased the capacitated (B pattern)

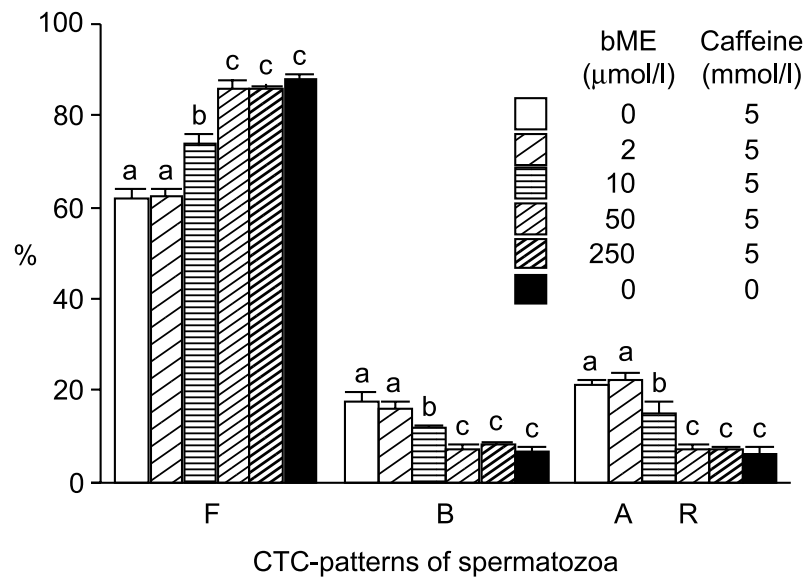

Figure 2 Effect of bME on sperm characteristics as determined by CTC fluorescence patterns in fresh boar spermatozoa: $F$, intact (uncapacitated) cells; B, capacitated cells; AR, acrosome-reacted cells. Spermatozoa were cultured in the absence or presence of various concentrations of bME in m-M199 or m-M199-caffeine for $2 \mathrm{~h}$. Different letters above the bars indicate statistically significant differences $(P<0.05)$.

and acrosome-reacted (AR pattern) cells. Although $2 \mu \mathrm{mol}$ bME/l did not affect $(P>0.05)$ the stimulatory effect of caffeine-benzoate, the presence of bME at more than $10 \mu \mathrm{mol} / \mathrm{l}$ neutralized the stimulatory effect of caffeinebenzoate in a concentration-dependent manner. CTC patterns of spermatozoa cultured in the presence of 50 and $250 \mu \mathrm{mol}$ bME/l in m-M199-caffeine did not differ from those of spermatozoa cultured in bME-free and caffeinefree m-M199.

\section{Effect of bME during transient IVF procedures on sperm penetration (experiment 2)}

As shown in Table 1, the presence of $50 \mu \mathrm{mol}$ bME/l during a transient co-culture of oocytes with spermatozoa for $10 \mathrm{~min}$ significantly reduced the percentage of oocytes penetrated at $9 \mathrm{~h}$ after insemination $(70.5 \pm 5.6$ to $82.0 \pm 7.5 \%$ vs $90.5 \pm 3.9$ to $94.0 \pm 2.3 \%$ in the absence of bME), but did not affect the incidence of monospermic penetration. On the other hand, when $50 \mu \mathrm{mol}$ bME/l were supplemented during the culture period following a transient co-culture, sperm penetration rate was not affected, but the incidence of monospermic penetration increased $(43.9 \pm 2.3$ to $45.8 \pm 3.1 \%$ vs $31.7 \pm 4.5$ to $34.3 \pm 1.9 \%$ in the absence of $\mathrm{bME})$. The presence of $50 \mu \mathrm{mol}$ bME/l during the same culture period also decreased both the mean number of spermatozoa in a penetrated oocyte $(1.4 \pm 0.1$ to $1.7 \pm 0.1$ cells/penetrated oocyte vs $2.0 \pm 0.2$ to $2.3 \pm 0.2$ cells/penetrated oocyte in the absence of bME) and the incidence of oocytes $(73.0 \pm 5.3$ to $85.3 \pm 6.5 \%$ vs $92.5 \pm 2.8$ to $94.6 \pm 1.7 \%$ in the absence of bME) at the pronuclear stage $9 \mathrm{~h}$ after insemination. 
Table 1 Effect of bME on sperm penetration into porcine IVM oocytes in a two-step IVF system*.

\begin{tabular}{|c|c|c|c|c|c|c|}
\hline \multirow{2}{*}{$\begin{array}{l}\text { Concentration of bME }(\mu \mathrm{mol} / \mathrm{l}) \text { : } \\
\text { During co-culture }(10 \mathrm{~min})\end{array}$} & \multicolumn{4}{|c|}{ Treatment } & \multicolumn{2}{|c|}{ Significance of effects ( $P$-value) } \\
\hline & 0 & 0 & 50 & 50 & & \\
\hline During the following culture & 0 & 50 & 0 & 50 & $\begin{array}{l}\text { DME durıng } \\
\text { co-culture }\end{array}$ & $\begin{array}{l}\text { bME during the following } \\
\text { culture }\end{array}$ \\
\hline No. of replicated trials & 10 & 10 & 8 & 10 & & \\
\hline No. of oocytes examined & 307 & 286 & 268 & 284 & & \\
\hline \multirow[t]{2}{*}{ No. of mature eggs (\%) } & 295 & 273 & 256 & 266 & & \\
\hline & $(96.0 \pm 1.1)$ & $(95.3 \pm 1.3)$ & $(95.4 \pm 1.2)$ & $(93.6 \pm 1.1)$ & 0.37 & 0.44 \\
\hline$\%$ of oocytes penetratedt & $94.0 \pm 2.3^{a}$ & $90.5 \pm 3.9^{\mathrm{a}}$ & $82.0 \pm 7.5^{\mathrm{ab}}$ & $70.5 \pm 5.6^{b}$ & $<0.01$ & 0.11 \\
\hline$\%$ of oocytes at the PN stage $\neq$ & $94.6 \pm 1.7^{\mathrm{a}}$ & $85.3 \pm 6.5^{\mathrm{a}}$ & $92.5 \pm 2.8^{\mathrm{a}}$ & $73.0 \pm 5.3^{\mathrm{b}}$ & 0.08 & 0.02 \\
\hline$\%$ of monospermyt & $31.7 \pm 4.5^{\mathrm{a}}$ & $43.9 \pm 2.3^{b c}$ & $34.3 \pm 1.9^{\mathrm{ab}}$ & $45.8 \pm 3.1^{\mathrm{c}}$ & 0.43 & $<0.01$ \\
\hline Sperm/penetrated egg & $2.3 \pm 0.2^{\mathrm{a}}$ & $1.7 \pm 0.1^{\mathrm{bc}}$ & $2.0 \pm 0.2^{\mathrm{ab}}$ & $1.4 \pm 0.1^{\mathrm{c}}$ & 0.08 & $<0.01$ \\
\hline
\end{tabular}

* After co-culture with spermatozoa $\left(2.5 \times 10^{5} \mathrm{cell} / \mathrm{s} / \mathrm{ml}\right)$ for $10 \mathrm{~min}$ in $\mathrm{m}-\mathrm{M}$ - 199 -caffeine, oocytes were subjected to the following culture in caffeine-free $\mathrm{m}-\mathrm{M} 199$ and fixed at $9 \mathrm{~h}$ after insemination.

+Percentage (mean \pm S.E.M.) in matured oocytes.

¥ Percentage (mean \pm S.E.M.) in penetrated oocytes.

Values with different superscripts within rows are significantly different $(P<0.05)$. $\mathrm{PN}$, pronucleus.

\section{Effect of bME during the culture period after a transient co-culture on oocyte glutathione content (experiment 3)}

As shown in Fig. 3, intracellular glutathione content was lower in the absence of bME during the culture period following a transient co-culture with spermatozoa $(5.5 \pm$ $0.2 \mathrm{pmol} / \mathrm{egg})$, as compared with that in the presence of bME $(6.7 \pm 0.3$ pmol/egg). However, the glutathione contents were significantly lower than those in IVM oocytes before insemination (7.9 $\pm 0.5 \mathrm{pmol} /$ oocyte).

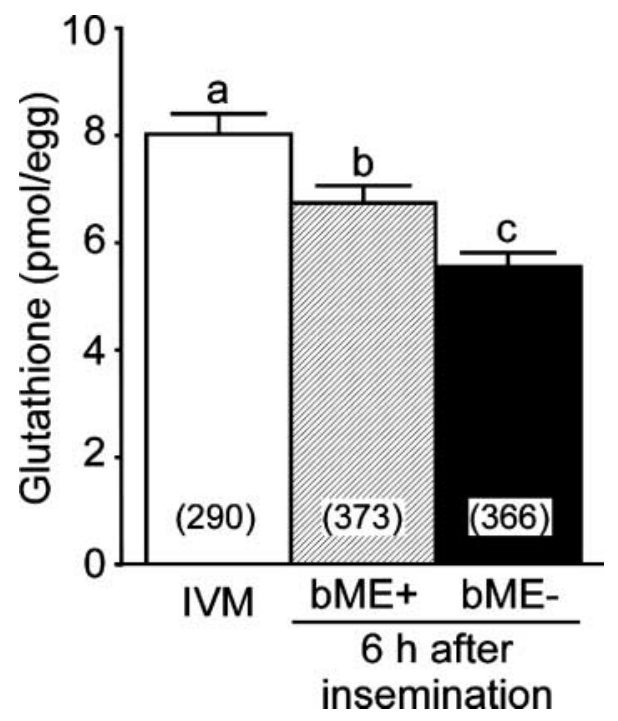

Figure 3 Glutathione contents of porcine oocytes before $(0 \mathrm{~h})$ and after a transient co-culture with spermatozoa for $10 \mathrm{~min}$ in $\mathrm{m}-\mathrm{M} 199$ caffeine and the following culture for $6 \mathrm{~h}$ in the absence or presence of bME in caffeine-free m-M199. Numbers in parentheses indicate the total number of oocytes assayed. Bars with different letters differ statistically $(P<0.05)$.

\section{Effect of bME on cortical granule exocytosis of oocytes activated with calcium-ionophore (experiment 4)}

When the distribution of PNA at the cortex region was examined at $1 \mathrm{~h}$ after oocyte treatment with calcium ionophore, pixel intensity was lower $(P<0.01)$ in oocytes treated and cultured in the presence of $50 \mu \mathrm{mol} \mathrm{bME} / \mathrm{l}$ (12.02 \pm 0.54$)$ as compared with those activated in the absence of bME (16.33 \pm 0.55 ; Fig. 4).

\section{Effect of bME during IVF procedures on early development (experiment 5)}

As shown in Table 2, the percentages of cleavage and blastocyst formation were lower when oocytes were cocultured with spermatozoa in the presence of $50 \mu \mathrm{mol}$

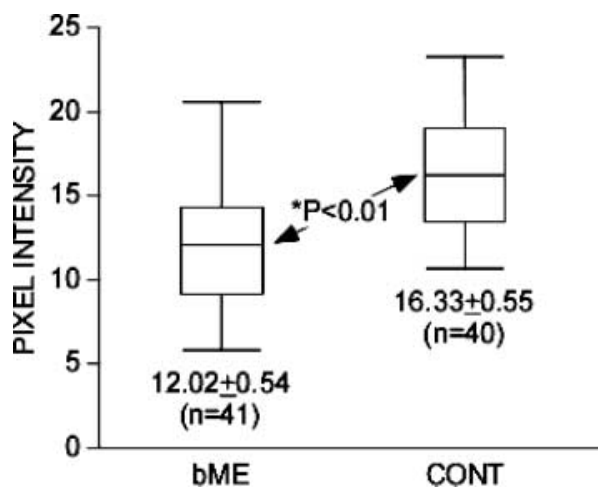

Figure 4 Degree of cortical granule exocytosis after calcium ionophore treatment, as evaluated by the distribution of FITC-PNA at the cortex region of oocytes. In the absence (CONT) or presence of $50 \mu \mathrm{mol}$ bME/l (bME), denuded oocytes were treated with calcium ionophore for $5 \mathrm{~min}$, cultured for $1 \mathrm{~h}$ and then processed. After taking out the background intensity, the mean pixel intensities of the cortex region of the oocytes were plotted. 
Table 2 In vitro development of porcine IVM oocytes fertilized in vitro* in the absence or presence of bME.

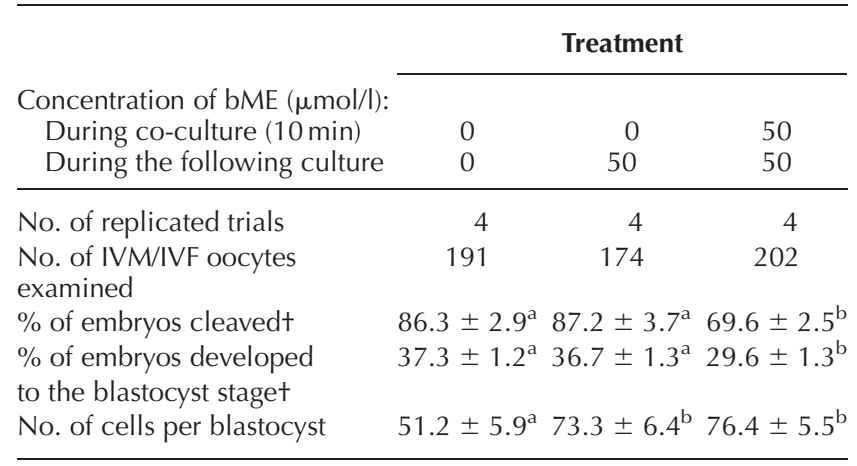

* Oocytes were co-cultured for $10 \mathrm{~min}$ with spermatozoa $\left(2.5 \times 10^{5}\right.$ cell $\mathrm{s} / \mathrm{ml}$ ) in $\mathrm{m}-\mathrm{M} 199$-caffeine and then culture continued in caffeinefree m-M199 for $6 \mathrm{~h}$ ('the following culture') followed by IVC in modified NCSU37 for 7 days.

t Percentage in total IVM/IVF oocytes examined.

${ }^{a b}$ Values with different superscripts within rows are significantly different $(P<0.05)$.

bME/l $\quad(69.6 \pm 2.5$ and $29.6 \pm 1.3 \%$ respectively). When oocytes were transiently co-cultured for $10 \mathrm{~min}$ with spermatozoa in bME-free m-M199-caffeine, the presence of bME during culture for $5 \mathrm{~h}$ and $50 \mathrm{~min}$ following a brief co-culture period did not affect the percentages of cleavage and blastocyst formation (87.2 \pm 3.7 and $36.7 \pm 1.3 \%$ vs $86.3 \pm 2.9$ and $37.3 \pm 1.2 \%$ in controls respectively). However, the presence of bME for the duration of the culture after a transient co-culture, regardless of the presence of bME during the co-culture, increased the mean cell numbers per blastocyst $(73.3 \pm 6.4$ to $76.4 \pm 5.5$ in the presence vs $51.2 \pm 5.9$ in the absence of bME).

\section{Discussion}

In the present study, when the effect of bME on sperm functions in m-M199-caffeine was determined by CTC fluorescence assessment after culture for $2 \mathrm{~h}$, the presence of bME at more than $10 \mu \mathrm{mol} / \mathrm{l}$ neutralized the stimulatory effect of caffeine to induce sperm capacitation and the spontaneous acrosome reaction. Caffeine is generally thought of as a molecule that inhibits cyclic nucleotide phosphodiesterase, resulting in an increase in intracellular cAMP (Casillas \& Hoskins 1970); therefore the present results demonstrate that bME prevents a signal pathway, probably existing downstream of the adenylyl cyclase/cAMP pathway, that is stimulated by caffeine. In the physiological condition in vivo, although spermatozoa are protected by various antioxidants and antioxidant enzymes in seminal plasma or in spermatozoa itself, reactive oxygen species trigger sperm hyperactivation, and may support the capacitation of spermatozoa and fertilization (Kim \& Parthasarathy 1998). Superoxide anions and hydrogen peroxide have been shown to participate in the induction of key events such as hyperactivated motility and the acrosome reaction in human spermatozoa in vitro (Aitken \& Fisher 1994). Furthermore, it has been demonstrated that adding vitamin $\mathrm{E}$ alone or together with vitamin $\mathrm{C}$ to the capacitation medium protects the plasma membrane against lipid peroxidation during sperm capacitation, and consequently against decreases in the percentage of capacitated bovine spermatozoa (O'Flaherty et al. 1997). Therefore, supplementation with antioxidants would protect lipid peroxidation associated with the reactive oxygen species signal pathway and would cause the inhibitory effect on sperm capacitation and the spontaneous acrosome reaction.

In the current study, fresh spermatozoa were co-cultured with oocytes for a transient period $(10 \mathrm{~min})$ in a fertilization decreased containing caffeine-benzoate just after washing, without preincubation to induce capacitation, and then only oocytes with binding spermatozoa were subjected to the following culture in caffeine-free m-M199 until $9 \mathrm{~h}$ after insemination. Supplementation with bME during a transient co-culture period decreased, but not completely, the incidence of sperm penetration, whereas bME in m-M199-caffeine prevented the stimulating effect of caffeine on sperm capacitation and the spontaneous acrosome reaction during culture for $2 \mathrm{~h}$. In a conventional IVF system, it has been reported that the addition of catalase during the co-culture period reduces sperm penetration rates in cows (Blondin et al. 1997). Supplementation with other antioxidants such as superoxide dismutase, catalase and $\mathrm{N}$-acetyl-L-cysteine, during IVF also decreases the subsequent rate of bovine embryo development to the morula and blastocyst stages (Ali et al. 2003). Therefore, these results suggest that, even during a short co-culture period, the presence of bME is effective in preventing to some extent, or delaying, capacitation of boar spermatozoa and consequently appears to reduce the incidence of sperm penetration (at $9 \mathrm{~h}$ after insemination).

In contrast, the presence of bME during culture in caffeine-free m-M199 after a transient co-culture significantly decreased the incidence of polyspermy oocytes and the mean number of spermatozoa in a penetrated egg, but did not affect sperm penetration rate. In the present study, to compare the effect of bME treatment on monospermic penetration directly, the incidence of monospermy was shown as a percentage of total mature oocytes examined. Thus, monospermy or polyspermy rates were not affected by the penetration rates. The results suggest that a transient co-culture period in the presence of caffeine-benzoate $(10 \mathrm{~min})$ should be enough to induce sperm capacitation and penetration, even when followed by an additional culture in the presence of bME in caffeine-free medium. Therefore, the current new IVF system - composed of a transient co-culture in $\mathrm{m}-\mathrm{M} 199$-caffeine and the following culture in the presence of bME in caffeine-free m-M199 - is valid for increasing the incidence of normally penetrated eggs 
without any reduction in penetration rate. However, the presence of bME during the culture after a transient coculture period reduced the incidence of penetrated oocytes developing to the pronuclear stage (by $9 \mathrm{~h}$ after insemination). bME during the culture period following a transient co-culture appears to delay the time of sperm penetration, rather than prevent pronuclear formation since it affects the sperm function associated with capacitation and acrosome reaction.

The current observations showed that oocyte glutathione content decreased during culture until $6 \mathrm{~h}$ following insemination. This observation is inconsistent with our previous observations that intracellular glutathione content decreased in oocytes penetrated in vitro (Funahashi et al. 1995), probably due to a sperm enzyme associated with degradation of glutathione (Funahashi et al. 1996). However, the presence of bME during the culture for $6 \mathrm{~h}$ following a transient co-culture with spermatozoa minimized the decrease in oocyte glutathione content, as compared with culture in the absence of bME. This evidence indicates that oocytes suffer oxidative stress during IVF, in contrast to conditions in the oviduct where the internal scavenger system reduces stress.

It has been reported that oocytes matured in the recent IVM conditions possess equal ability to release cortical granules on sperm penetration in vitro when compared with in vivo-matured porcine oocytes (Wang et al. 1998a). However, the current data demonstrate that the presence of bME during chemical activation of oocytes significantly improved the degree of cortical granule exocytosis of IVM oocytes $1 \mathrm{~h}$ after activation and that supplementation with bME during culture following a transient co-culture, the period of sperm penetration, decreased the incidence of polyspermic penetration. Thus, the rate of cortical exocytosis may be reduced even during IVF processes, by the oxidative stress. Although Boquest et al. (1999) have reported that the addition of glutathione during insemination did not affect the rate of polyspermic fertilization, the polyspermy rate was reduced even in oocytes matured in a medium supplemented with bME (Whitaker 1990, Mizushima \& Fukui 2001). In the present study, oocyte glutathione content was higher when oocytes were cultured in a medium containing bME following a transient co-culture. Therefore, supplementation with bME during IVM and sperm penetration not only affects the sperm function associated with fertilization, but also minimizes the decrease in intracellular glutathione content of oocytes during sperm penetration and somewhat improves the degree of cortical granule exocytosis, and consequently appears to reduce the incidence of polyspermic penetration.

The addition of antioxidants, such as cysteine (Ali et al. 2003), ascorbic acid (Comizzoli et al. 2000, Tatemoto et al. 2001), cysteamine (Rodriguez-Gonzalez et al. 2003), I-alpha-aminobutyrate (Whitaker 1990) and bME
(Whitaker 1990, Mizushima \& Fukui 2001), during IVM improves oocyte glutathione concentrations and early development to the blastocyst stage after IVF in several species. However, these effects appear to be dependent on species and antioxidants (de Matos et al. 2002, Songsasen \& Apimeteetumrong 2002). In pigs, supplementation with cysteine and bME during IVM improved oocyte competence to develop to the blastocyst stage after IVF (Funahashi et al. 1997, Abeydeera et al. 1998). Therefore, storage of transcripts encoding for antioxidant enzymes during oocyte maturation could be important in pigs in order to allow the embryo to acquire the aptitude to develop (Guerin et al. 2001). The incidence of blastocyst formation and the quality of embryos have also been enhanced by reducing the oxidative stress during IVC after IVF (Caamano et al. 1996, Kikuchi et al. 2002, Takahashi et al. 2002). In the present study, when bME was supplemented during the culture period after a transient coculture, the percentage blastocyst formation was not improved. However, the decrease in intracellular glutathione content was minimized, and the degree of cortical reaction at oocyte activation, the incidence of monospermic penetration and the quality of embryos (as determined by the number of cells in a blastocyst) were improved. Furthermore, the presence of bME during a transient coculture of gametes for only $10 \mathrm{~min}$ decreased the incidence of blastocyst formation, probably due to a decreased incidence of sperm penetration, but did not affect the incidence of monospermic penetration and the quality of embryos. It has also been shown that although polyspermic IVM-IVF porcine embryos containing multiple pronuclei can develop to the blastocyst stage at the same percentage as monospermic IVM-IVF embryos, the mean cell number of blastocysts (especially inner cell mass) derived from polyspermic embryos was lower than that of monospermic blastocysts (Han et al. 1999). Therefore, a reduction in oxidative stress in oocytes during sperm penetration in vitro, by adding bME after a transient co-culture, appears to improve the incidence of monospermic penetration by affecting the oocyte function associated with fertilization, and consequently the quality of blastocysts.

In conclusion, supplementation with thiol components during IVF procedures, except for a transient co-culture period permitting sperm capacitation and/or sperm-zona binding, has several beneficial effects: preventing excessive sperm capacitation; minimizing the decrease in oocyte glutathione content through sperm penetration; promoting cortical granule exocytosis; and increasing the incidence of normal fertilization. These beneficial effects of bME consequently appear to improve the quality of IVF embryos. 


\section{Acknowledgements}

The author thanks the Okayama Prefectural Center for Animal Husbandry and Research for supplying fresh boar semen. This work was supported by grants from the Ito Foundation and Grant-in-Aid for Scientific Research (C16580230) of the Japan Society for the Promotion of Science. The authors declare that there is no conflict of interest that would prejudice the impartiality of this scientific work.

\section{References}

Abeydeera LR, Wang WH, Cantley TC, Prather RS \& Day BN 1998 Presence of beta-mercaptoethanol can increase the glutathione content of pig oocytes matured in vitro and the rate of blastocyst development after in vitro fertilization. Theriogenology $\mathbf{5 0}$ 747-756.

Aitken J \& Fisher H 1994 Reactive oxygen species generation and human spermatozoa: the balance of benefit and risk. Bioessays $\mathbf{1 6}$ $259-267$.

Ali AA, Bilodeau JF \& Sirard MA 2003 Antioxidant requirements for bovine oocytes varies during in vitro maturation, fertilization and development. Theriogenology 59 939-949.

Anderson ME 1985 Determination of glutathione and glutathione disulfide in biological samples. In Methods in Enzymology, vol 113, Glutamate, Glutamine, Glutathione, and Related Compounds, pp 548-555. Ed. A Meister. Academic Press, San Diego.

Blondin P, Coenen K \& Sirard MA 1997 The impact of reactive oxygen species on bovine sperm fertilizing ability and oocyte maturation. Journal of Andrology 18 454-460.

Boquest AC, Abeydeera LR, Wang WH \& Day BN 1999 Effect of adding reduced glutathione during insemination on the development of porcine embryos in vitro. Theriogenology $\mathbf{5 1}$ 1311-1319.

Caamano JN, Ryoo ZY, Thomas JA \& Youngs CR 1996 Beta-mercaptoethanol enhances blastocyst formation rate of bovine in vitromatured/in vitro-fertilized embryos. Biology of Reproduction $\mathbf{5 5}$ 1179-1184.

Calvin HI, Grosshans K \& Blake EJ 1986 Estimation and manipulation of glutathione levels in prepuberal mouse ovaries and ova: relevance to sperm nucleus transformation in the fertilized egg. Gamete Research 14 265-275.

Casillas ER \& Hoskins DD 1970 Activation of monkey spermatozoa adenyl cyclase by thyroxine and triiodothyronine. Biochemical and Biophysical Research Communications 40 255-262.

Comizzoli P, Marquant-Le Guienne B, Heymen Y \& Renard JP 2000 Onset of the first S-phase is determined by a paternal effect during the G1-phase in bovine zygotes. Biology of Reproduction 62 1677-1684.

de Lamirande E \& Gagnon C 1993 Human sperm hyperactivation and capacitation as parts of an oxidative process. Free Radical Biology and Medicine 14 157-166.

de Matos DG, Gasparrini B, Pasqualini SR \& Thompson JG 2002 Effect of glutathione synthesis stimulation during in vitro maturation of ovine oocytes on embryo development and intracellular peroxide content. Theriogenology 57 1443-1451.

Funahashi H 2003 Polyspermic penetration in porcine IVM-IVF systems. Reproduction, Fertility and Development 15 167-177.

Funahashi H \& Romar R 2004 Reduction of the incidence of polyspermic penetration into porcine oocytes by pretreatment of fresh spermatozoa with adenosine and a transient co-incubation of the gametes with caffeine. Reproduction 128 789-800.

Funahashi H \& Sato T 2005 Select antioxidants improve the function of extended boar semen stored at $10^{\circ} \mathrm{C}$. Theriogenology 63 1605-1616.

Funahashi H, Cantley TC \& Day BN 1994a Different hormonal requirement of porcine oocyte-complexes during maturation in vitro. Journal of Reproduction and Fertility 101 159-165.
Funahashi H, Cantley TC, Stumpf TT, Terlouw SL \& Day BN 1994b Use of low salt culture medium for in vitro maturation of porcine oocytes is associated with elevated oocyte glutathione levels and enhanced male pronuclear formation after in vitro fertilization. Biology of Reproduction 51 633-639.

Funahashi H, Stumpf TT, Cantley TC, Kim NH \& Day BN 1995 Pronuclear formation and intracellular glutathione content of in vitro-matured porcine oocytes following in vitro fertilisation and/or electrical activation. Zygote 3 273-281.

Funahashi H, Machaty Z, Prather RS \& Day BN $1996 \gamma$-Glutamyltranspeptidase of spermatozoa may decrease oocyte glutathione content at fertilization in pigs. Molecular Reproduction and Development 45 485-490.

Funahashi H, Cantley TC \& Day BN 1997 Synchronization of meiosis in porcine oocytes by exposure to dibutyryl cyclic adenosine monophosphate improves developmental competence following in vitro fertilization. Biology of Reproduction 57 49-53.

Funahashi H, Asano A, Fujiwara T, Nagai T, Niwa K \& Fraser LR 2000 Both fertilization promoting peptide and adenosine stimulate capacitation but inhibit spontaneous acrosome loss in ejaculated boar spermatozoa in vitro. Molecular Reproduction and Development 55 117-124.

Guerin P, El Mouatassim S \& Menezo Y 2001 Oxidative stress and protection against reactive oxygen species in the pre-implantation embryo and its surroundings. Human Reproduction Update 7 175-189.

Han YM, Abeydeera LR, Kim JH, Moon HB, Cabot RA, Day BN \& Prather RS 1999 Growth retardation of inner cell mass cells in polyspermic porcine embryos produced in vitro. Biology of Reproduction $601110-1113$.

Katayama M, Koshida M \& Miyake M 2002 Fate of the acrosome in ooplasm in pigs after IVF and ICSI. Human Reproduction 17 2657-2664.

Kikuchi K, Onishi A, Kashiwazaki N, Iwamoto M, Noguchi J, Kaneko H, Akita T \& Nagai T 2002 Successful piglet production after transfer of blastocysts produced by a modified in vitro system. Biology of Reproduction 66 1033-1041.

Kim JG \& Parthasarathy S 1998 Oxidation and the spermatozoa. Seminars in Reproductive Endocrinology 16 235-239.

Leclerc P, de Lamirande E \& Gagnon C 1997 Regulation of proteintyrosine phosphorylation and human sperm capacitation by reactive oxygen derivatives. Free Radical Biology and Medicine 22 643-656.

Mizushima S \& Fukui Y 2001 Fertilizability and developmental capacity of bovine oocytes cultured individually in a chemically defined maturation medium. Theriogenology 55 1431-1445.

O'Flaherty C, Beconi M \& Beorlegui N 1997 Effect of natural antioxidants, superoxide dismutase and hydrogen peroxide on capacitation of frozen-thawed bull spermatozoa. Andrologia 29 $269-275$.

Petters RM \& Wells KD 1993 Culture of pig embryos. Journal of Reproduction and Fertility, Supplement $4861-73$.

Rodriguez-Gonzalez E, Lopez-Bejar M, Mertens MJ \& Paramio MT 2003 Effects on in vitro embryo development and intracellular glutathione content of the presence of thiol compounds during maturation of prepubertal goat oocytes. Molecular Reproduction and Development 65 446-453.

Songsasen N \& Apimeteetumrong M 2002 Effects of beta-mercaptoethanol on formation of pronuclei and developmental competence of swamp buffalo oocytes. Animal Reproduction Science $\mathbf{7 1}$ 193-202.

Takahashi M, Nagai T, Okamura N, Takahashi H \& Okano A 2002 Promoting effect of beta-mercaptoethanol on in vitro development under oxidative stress and cystine uptake of bovine embryos. Biology of Reproduction $66562-567$.

Wang WH, Abeydeera LR, Prather RS \& Day BN 1998a Morphologic comparison of ovulated and in vitro-matured porcine oocytes, with particular reference to polyspermy after in vitro fertilization. Molecular Reproduction and Development 49 308-316. 
Wang WH, Machaty Z, Abeydeera LR, Prather RS \& Day BN 1998 b Parthenogenetic activation of pig oocytes with calcium ionophore and the block to sperm penetration after activation. Biology of Reproduction 58 1357-1366.

Whitaker MJ 1990 Cell cycle control proteins are second messenger targets at fertilization in sea-urchin eggs. Journal of Reproduction and Fertility, Supplement 42 199-204.

Wongsrikeao P, Karja NWK, Budiyanto A, Mtango NR, Murakami M, Nii M \& Otoi T 2004 Meiotic competence and DNA fragmentation of porcine oocytes from ovaries stored in various temperatures. Reproduction, Fertility and Development 16 283-284.

Received 23 February 2005

First decision 19 May 2005

Revised manuscript received 27 August 2005

Accepted 8 September 2005 